\title{
Self-Amplified Fluorescent Nanoparticles (SAFNs) for Rapid and Visual Detection of Xylene in Aqueous Media
}

Ping Ge,${ }^{\dagger}$ Yusheng Zhou, ${ }^{\dagger}$ Jialong Wu, ${ }^{\dagger}$ Fangming Zhu, ${ }^{\dagger}$ Mingliang Ge ${ }^{\ddagger}$ and Guodong Liang*广

†PCFM lab, School of Materials Science and Engineering, Sun Yat-Sen University, Guangzhou, 510275, China.

Key Laboratory of Polymer Processing Engineering, South China University of Technology, Ministry of Education, Guangzhou, 510640, China.

\section{Synthesis.}

\section{Synthesis of Tetraphenylethene (TPE).}

A three-necked flask equipped with a magnetic stirrer was charged with zinc powder (7.85 g; $120 \mathrm{mmol}$ ) and $150 \mathrm{~mL}$ THF under $\mathrm{N}_{2}$ atmosphere. The mixture was cooled to -5 to $0{ }^{\circ} \mathrm{C}$, and $\mathrm{TiCl}_{4}(6.5 \mathrm{~mL} ; 60 \mathrm{mmol})$ was slowly added by a syringe under $10{ }^{\circ} \mathrm{C}$. The mixture was restored to room temperature and stirred for $0.5 \mathrm{~h}$, then reflux for $2.5 \mathrm{~h}$. The mixture was cooled to -5 to $0{ }^{\circ} \mathrm{C}$, charged with pyridine $(2.5 \mathrm{~mL} ; 30$ mmol) and stirred for $10 \mathrm{~min}$. To the mixture was added $4.37 \mathrm{~g}$ benzophenone (24 mmol). The reaction mixture was refluxed for $24 \mathrm{~h}$ until the benzophenone was consumed (followed by TLC). The reaction was quenched with $20 \mathrm{~mL}$ of $10 \% \mathrm{~K}_{2} \mathrm{CO}_{3}$ 
aqueous solution, and filtrated to remove solid. The product was extracted with dicholomethane $(50 \mathrm{~mL} \times 3)$. The organic layers were combined, washed with saturated brine solution and dried over anhydrous magnesium sulphate. The solvent was removed under reduced pressure to yield crude product. The crude product was purified by silica chromatography using hexane as eluent to give the desired products of tetraphenylethene (TPE). Yield 65\%. The compound emitted efficiently blue light under $365 \mathrm{~nm}$ radiation. ${ }^{1} \mathrm{H} \mathrm{NMR}\left(400 \mathrm{MHz}, \mathrm{CDCl}_{3}\right.$ ), $\delta$ (TMS, ppm): 6.9-7.0 (m, 12 $\mathrm{H}, \mathrm{Ar}-\mathrm{H}), 7.0-7.2(\mathrm{~m}, 8 \mathrm{H}, \mathrm{Ar}-\mathrm{H})$. The ${ }^{1} \mathrm{H}$ NMR spectrum agreed with literature data. $^{1-2}$

Scheme S1. Synthetic Route for Tetraphenylethene (TPE).<smiles>O=C(c1ccccc1)c1ccccc1</smiles>

\section{Synthesis of 4-(1,2,2-Triphenylvinyl)benzoic acid (TPEC).}

1-(4-Bromophenyl)-1,2,2-triphenylethene (TPE-Br). The compound was synthesized according to the synthetic route shown in Scheme S3. Typical procedures were shown as follows. To a solution of diphenylmethane $(2.02 \mathrm{~g} ; 12 \mathrm{mmol})$ in dry tetrahydrofuran $(50 \mathrm{~mL})$ was added $6.25 \mathrm{~mL}$ of a $1.6 \mathrm{M}$ solution of $n$-butyllithium in hexane $(10 \mathrm{mmol})$ at $-78{ }^{\circ} \mathrm{C}$ under nitrogen. The resulting orange-red solution was stirred for $30 \mathrm{~min}$ at that temperature. To this solution was added 4-bromobenzophenone (2.35 $\mathrm{g} ; 9 \mathrm{mmol})$. Afterwards, the reaction mixture was allowed to warm to room temperature and stirred for another $6 \mathrm{~h}$. The reaction was 
quenched with the addition of an aqueous solution of ammonium chloride. The organic layer was then extracted with dichloromethane $(50 \mathrm{~mL} \times 3)$. The organic layers were combined, washed with saturated brine solution and dried over anhydrous magnesium sulphate. After solvent evaporation, the resulting crude alcohol (containing excess diphenylmethane) was subjected to acid-catalyzed dehydration without further purification. The crude alcohol was dissolved in about $80 \mathrm{~mL}$ of toluene in a $100 \mathrm{~mL}$ Schlenk flask fitted with a Dean-Stark trap. A catalytic amount of p-toluenesulfonic acid (342 $\mathrm{mg} ; 1.8 \mathrm{mmol})$ was added and the mixture was refluxed for 3-4 h. After the reaction mixture was cooled to room temperature, the toluene layer was washed with $10 \%$ aqueous $\mathrm{NaHCO}_{3}$ solution $(25 \mathrm{~mL} \times 2)$ and dried over anhydrous magnesium sulfate. Evaporation of the solvent under reduced pressure afforded the crude tetraphenylethene derivative, which was further purified by silica gel column chromatography using hexane as eluent. Yield 92\%. ${ }^{1} \mathrm{H}$ NMR (400 MHz, DMSO- $\left.d_{6}\right), \delta$ (TMS, ppm): 6.95-7.11 (m, $\left.17 \mathrm{H}, \mathrm{Ar}-\mathrm{H}\right), 7.32$ (d, 2H, Ar-H).

4-(1,2,2-Triphenylvinyl)benzoic acid (TPEC). To a solution of 1 (1.6 g; 3.89 mmol) in $30 \mathrm{~mL}$ dry THF was added dropwise $2.9 \mathrm{~mL}(4.64 \mathrm{mmol})$ of $n$-butyllithium (1.6 $\mathrm{M}$ in $n$-hexane) at $-78{ }^{\circ} \mathrm{C}$ under stirring. The reaction mixture was stirred for $2 \mathrm{~h}$ to get a dark brown solution. To the obtained solution was then added dry ice pieces in small portions under nitrogen. The solution was allowed to warm to room temperature and stir for additional $12 \mathrm{~h}$. The solvent was evaporated under reduced pressure. The crude product was purified on a silica-gel column using dichloromethane/methanol mixture $(90 / 10 \mathrm{v} / \mathrm{v})$ as eluent. Yield 85\%. ${ }^{1} \mathrm{H}$ NMR (400 MHz, DMSO-d $\left.d_{6}\right), \delta$ (TMS, ppm): 6.95-7.11 (m, $\left.17 \mathrm{H}, \mathrm{Ar}-\mathrm{H}\right), 7.66(\mathrm{~d}, 2 \mathrm{H}, \mathrm{Ar}-\mathrm{H})$. ${ }^{13} \mathrm{C}$ NMR (400 MHz, $\left.\mathrm{CD}_{3} \mathrm{OD}\right), \delta$ (TMS, ppm): 125.9, 126.8, 128.3 and 130.3 (Ar), 142.4 and $141.8(\mathrm{C}=\mathrm{C}), 148.1(\mathrm{Ar}), 167.8\left(\mathrm{CO}_{2} \mathrm{H}\right)$. HRMS (MALDF-TOF): $\mathrm{m} / \mathrm{z}$ 
$376.1458\left(\mathrm{M}^{+}\right.$, calcd 376.1463).

Scheme S2. Synthetic Route for TPEC.

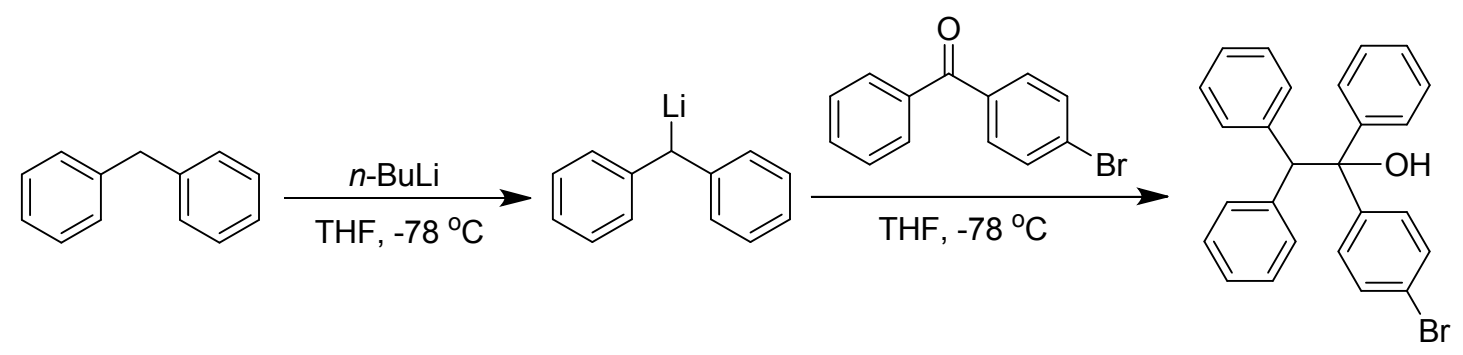

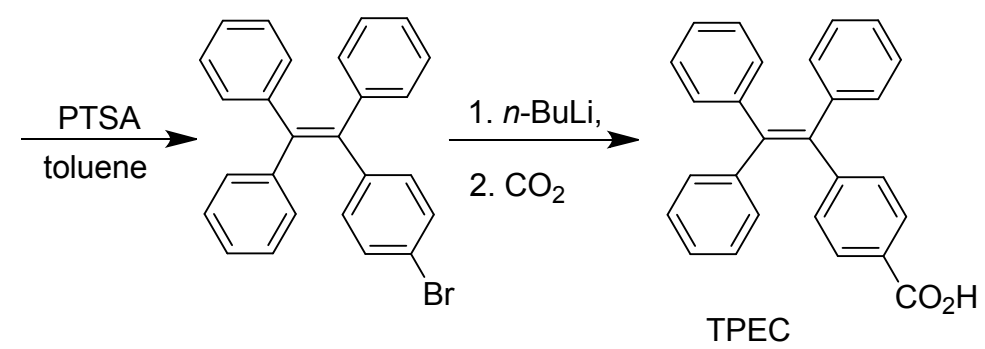

\section{Synthesis of 4-(1,2,2-triphenylvinyl)benzaldehyde (TPEA)}

To a solution of TPE-Br $(0.8 \mathrm{~g}, 2 \mathrm{mmol})$ in $20 \mathrm{~mL}$ dried THF was added dropwise 1.5 $\mathrm{mL}(2.4 \mathrm{mmol}) \mathrm{n}$-BuLi (1.6 $\mathrm{M}$ in $\mathrm{n}$-hexene) at $-78{ }^{\circ} \mathrm{C}$ with stirring. The reaction solution was stirred for $2 \mathrm{~h}$ to get a dark brown solution. To the obtained solution was added $5 \mathrm{~mL}$ N-Formylpiperidine $(65 \mathrm{mmol})$. The reaction solution was allowed to restore to room temperature and stir for $12 \mathrm{~h}$. The reaction was quenched with the addition of an aqueous solution of ammonium chloride. The organic layer was extracted with dichloromethane $(50 \mathrm{~mL} \times 3)$, and the combined organic layers were washed with a saturated brine solution and dried over anhydrous $\mathrm{MgSO}_{4}$. The solvent was evaporated. The crude product was purified by passing a silica column using hexane/ethyl acetate $(\mathrm{v} / \mathrm{v}=4 / 1)$ as eluent, finally obtaining compound 5 as a yellow solid (yield: 64\%). ${ }^{1} \mathrm{H}$ NMR (400 MHz, DMSO-d $), \delta$ (TMS, ppm): 7.00 (d, 3H, Ar- 
H), $7.16(\mathrm{~m}, 14 \mathrm{H}, \mathrm{Ar}-\mathrm{H}), 7.67$ (d, 2H, Ar-H), 9.88 (s, 1H, CHO).

Scheme S3. Synthetic Route for TPEA.

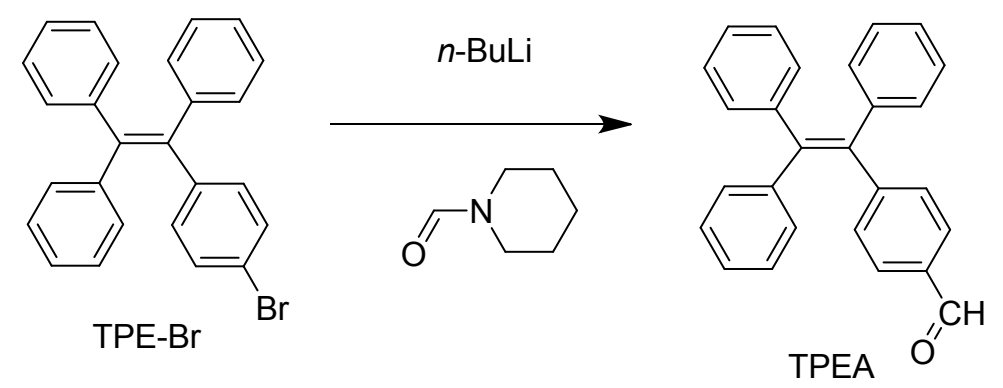

\section{Synthesis of 4-(1,2,2-triphenylvinyl)phenol (TPEH)}

A three-necked flask equipped with a magnetic stirrer was charged with zinc powder (7.85 g; $120 \mathrm{mmol}$ ) and $150 \mathrm{~mL}$ THF under $\mathrm{N}_{2}$ atmosphere. The mixture was cooled to -5 to $0{ }^{\circ} \mathrm{C}$, and $\mathrm{TiCl}_{4}(6.5 \mathrm{~mL} ; 60 \mathrm{mmol})$ was slowly added by a syringe under $10{ }^{\circ} \mathrm{C}$. The mixture was restored to room temperature and stirred for $0.5 \mathrm{~h}$, then reflux for $2.5 \mathrm{~h}$. The mixture was cooled to -5 to $0{ }^{\circ} \mathrm{C}$, charged with pyridine $(2.5 \mathrm{~mL} ; 30$ mmol) and stirred for $10 \mathrm{~min}$. To the mixture was added $2.19 \mathrm{~g}$ of benzophenone (12 mmol) and $2.38 \mathrm{~g}$ of (4-hydroxyphenyl)(phenyl)methanone $(12 \mathrm{mmol})$. The reaction mixture was refluxed for $24 \mathrm{~h}$ until the benzophenone was consumed (followed by TLC). The reaction was quenched with $20 \mathrm{~mL}$ of $10 \% \mathrm{~K}_{2} \mathrm{CO}_{3}$ aqueous solution, and filtrated to remove solid. The product was extracted with dicholomethane $(50 \mathrm{~mL} \times 3)$. The organic layers were combined, washed with saturated brine solution and dried over anhydrous magnesium sulphate. The solvent was removed under reduced pressure to yield crude product. The crude product was purified by column chromatography on silica gel using petroleum ether/dichloromethane mixture as an 
eluent, affording solid powders in $42 \%$ yield. ${ }^{1} \mathrm{H} \mathrm{NMR}\left(400 \mathrm{MHz}, \mathrm{CDCl}_{3}\right), \delta$ (TMS, ppm): 7.12-6.99 (m, 15H), $6.89(\mathrm{~d}, 2 \mathrm{H}), 6.56(\mathrm{~d}, 2 \mathrm{H}), 4.55(\mathrm{~s}, 1 \mathrm{H}) ;{ }^{13} \mathrm{C}$ NMR $(100$ $\left.\mathrm{MHz}, \mathrm{CDCl}_{3}\right), \delta$ (TMS, ppm): 154.12, 144.13, 144.04, 144.02, 140.57, 140.36, 136.55, $132.88,131.50,131.48,131.46,131.44,127.85,127.75,127.70,126.52,126.41$, 114.73. ESI-TOF calcd. for $\mathrm{C}_{26} \mathrm{H}_{19} \mathrm{O}[\mathrm{M}-\mathrm{H}]^{+}, 347.1441$, found $347.1441\left(\mathrm{M}^{+}\right)$.

Scheme S4. Synthetic Route for TPEH.<smiles>O=C(c1ccccc1)c1ccc(C(=O)c2ccccc2)cc1</smiles><smiles>Oc1ccc(C(=C(c2ccccc2)c2ccccc2)c2ccccc2)cc1</smiles>

\section{Calculation of the Aggregation Number of TPEC SAFNs}

Based on the spherical morphology TPEC SAFNS, the aggregation number, $N$, of TPEC SAFNS was estimated from the following formula:

$N=N_{\mathrm{A}} \cdot d \cdot V / M$

where $N_{\mathrm{A}}$ is Avogadro's number $\left(6.02 \times 10^{23}\right), M$ is molecular weight of TPEC (376.5 $\mathrm{g} / \mathrm{mol}), d$ is density of TPEC $\left(1.183 \mathrm{~g} / \mathrm{cm}^{3}\right), V$ is volume of each particles, calculated using $V=4 / 3 \pi(D / 2)^{3}$ ( $D$ denotes diameter of the SAFNs, being $78 \mathrm{~nm}$ ).

$N=N_{\mathrm{A}} \cdot d \cdot V / M$

$=6.02 \times 10^{23} / \mathrm{mol} \times 1.183 \mathrm{~g} / \mathrm{cm}^{3} \times 4 / 3 \pi \times\left(78 / 2 \times 10^{-7} \mathrm{~cm}\right)^{3} /(376.5 \mathrm{~g} / \mathrm{mol})$

$=4.70 \times 10^{5}$ 


\section{Estimation of the Number of Xylene Molecules in each TPEC SAFN}

The number of TPEC SAFNs in per liter of aqueous solution, $N_{\mathrm{m}}$, can be calculated $\operatorname{using} N_{\mathrm{m}}=N_{\mathrm{A}} \cdot C /(M \cdot N)$

where $C$ is the concentration of TPEC, $0.02 \mathrm{mg} / \mathrm{mL}$.

$N_{\mathrm{m}}=N_{\mathrm{A}} \cdot C /(M \cdot N)$

$=6.02 \times 10^{23} / \mathrm{mol} \times 0.02 \mathrm{mg} / \mathrm{mL} /\left(376.5 \mathrm{~g} / \mathrm{mol} \times 4.70 \times 10^{5}\right)$

$=6.80 \times 10^{13} / \mathrm{L}$.

In the presence of $5 \mu \mathrm{g} / \mathrm{L}$ of xylene, the number of xylene molecules in per liter of aqueous solution, $N_{\mathrm{x}}$, can be calculated using $N_{\mathrm{x}}=\left(N_{\mathrm{A}} \times 5 \mu \mathrm{g} / \mathrm{L}\right) /(106$ $\mathrm{g} / \mathrm{mol})=2.84 \times 10^{16} / \mathrm{L}$.

In the presence of $5 \mu \mathrm{g} / \mathrm{L}$ of xylene, the number of xylene molecules in each TPEC SAFN is $N_{\mathrm{x}} / N_{\mathrm{m}}=2.84 \times 10^{16} / 6.80 \times 10^{13}=418$

\section{Estimation of Molar Ratio of Xylene to TPE Moieties}

The molar ratio of xylene molecules to TPE moieties is calculated using $N_{\mathrm{x}} /\left(1 \times N \times N_{\mathrm{m}}\right)=2.84 \times 10^{16} /\left(1 \times 4.70 \times 10^{5} \times 6.80 \times 10^{13}\right)=8.9 \times 10^{-4}$ 


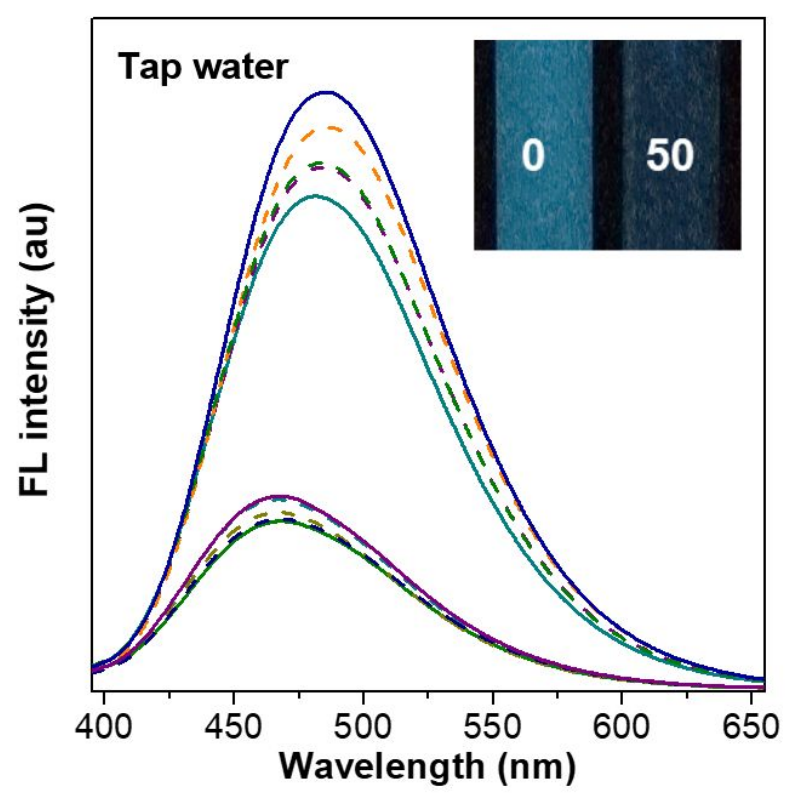

Figure S1. Fluorescence spectra of TPEC SAFNs in tap water in the absence and presence of xylene $(50 \mathrm{mg} / \mathrm{L})$. Inset showed the digital images of TPEC SAFNs containing various concentrations of xylene. Five parallel measurements were carried out for checking reproducibility.

Tap water was taken in our laboratory and used without further purification. No xylene was detected in tap water using GC-MS and UV-vis spectra. Thus, xylene is spiked into tap water as test samples (containing $100 \mathrm{mg} / \mathrm{mL}$ of xylene). 

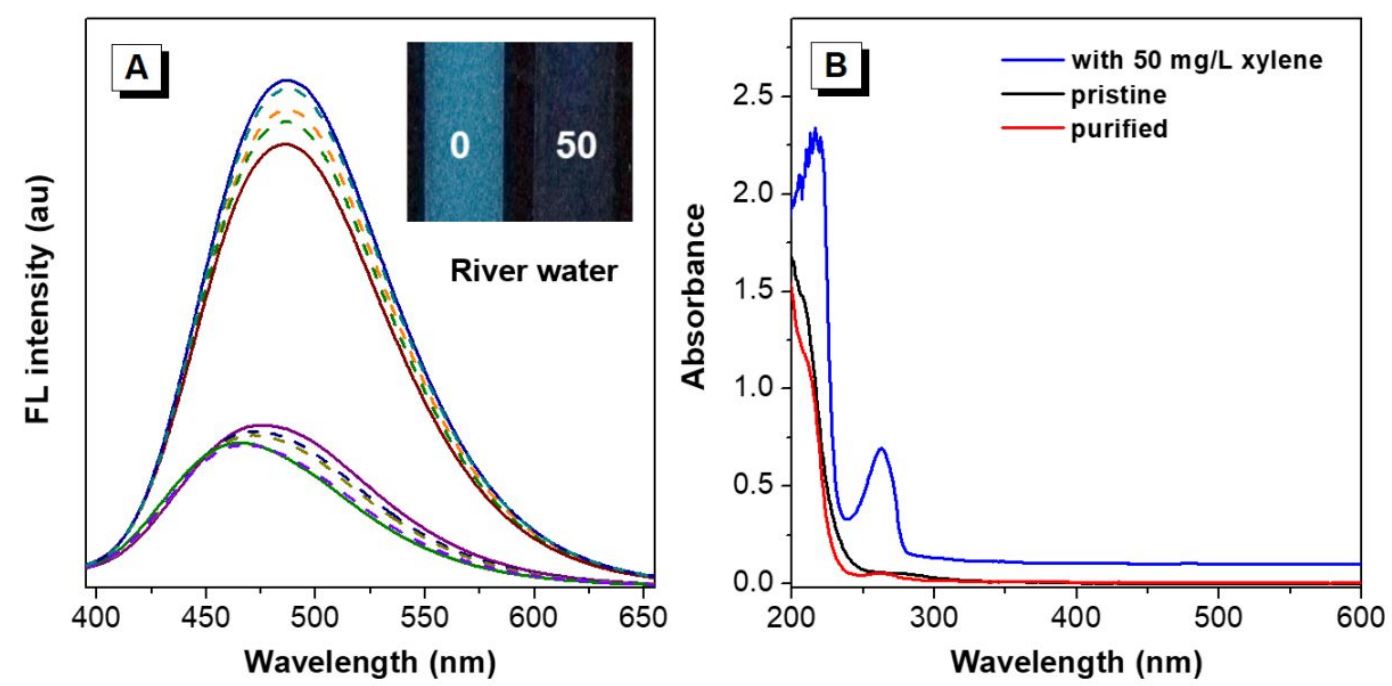

Figure S2. Fluorescence spectra of TPEC SAFNs in river water in the absence and presence of xylene $(50 \mathrm{mg} / \mathrm{L})$. Inset showed the digital images of TPEC SAFNs containing various concentrations of xylene. Five parallel measurements were carried out for checking reproducibility.

The river water was taken from Pearl River (Zhongda dock) and filtrated through 220 $\mathrm{nm}$ filters to remove insoluble objects. No xylene was detected in the river water using GC-MS and UV-vis spectra. Thus, xylene is also spiked into the river water as test samples (containing $100 \mathrm{mg} / \mathrm{mL}$ of xylene). 


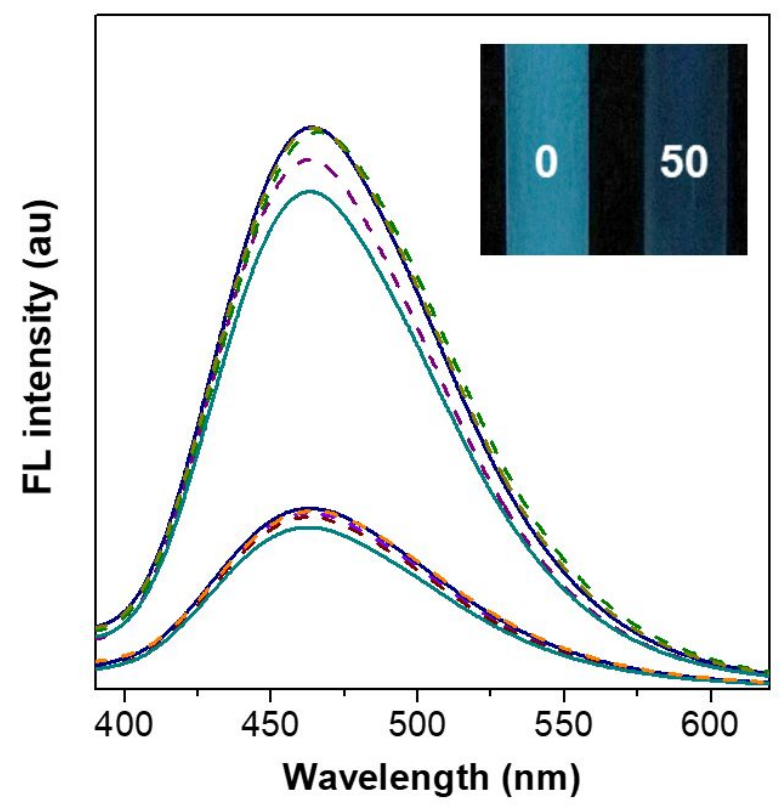

Figure S3. Fluorescence spectra of TPEC SAFNs in river water in the absence and presence of xylene $(50 \mathrm{mg} / \mathrm{L})$. Inset showed the digital images of TPEC SAFNs containing various concentrations of xylene. Five parallel measurements were carried out for checking reproducibility. The purified river water using activated carbon was used to prepare reference samples.

The xylene-spiked river water is further used as the only sample source for xylene detection. To acquire the reference samples with similar salt background, the polluted water (xylene-spiked river water) was purified using activated carbon. Activated carbon is used to removed aromatic pollutants such as xylene from the test sample but leave salt ions intact. In a typical run, $2 \mathrm{~g}$ of activated carbon powders were added into $10 \mathrm{~mL}$ of xylene-spiked river water. The mixture was shaken for $2 \mathrm{~min}$, followed by filtering off carbon powders. The clear filtrate was used to prepare reference samples. 


\section{References}

(1) Liang, G. D.; Weng, L. T.; Lam, J. W. Y.; Qin, W.; Tang, B., Crystallization-Induced Hybrid Nano-Sheets of Fluorescent Polymers with Aggregation-Induced Emission Characteristics for Sensitive Explosive Detection. ACS Macro Lett. 2014, 3, 21-25.

(2) Liang, G. D.; Lam, J. W. Y.; Qin, W.; Li, J.; Xie, N.; Tang, B. Z., Molecular luminogens based on restriction of intramolecular motions through host-guest inclusion for cell imaging. Chem. Commun. 2014, 50, 1725-1727. 